(3) Will this issue:

Allow the Chairman to speak for ten minutes without interruption

Allow a Committee Member to reply for ten minutes without interruption

Lead to extensive discussion

Engender universal agreement

(4) Can this matter be:

Subsumed to another agenda item

Referred to another committee

Spoken to by an elective mute

Seized on by the Press

(5) Does this matter concern:

The public's alcohol consumption

Doctors' alcohol consumption

Psychiatrists' alcohol consumption

College profits from brewery shares

(6) ( ) -10

( ) 5

( ) 10

All Committee Members ( ) -5

The College Membership （ ） -10

(7) This issue might give rise to:

A Special Interest

Group

A new Section

The resignation of a

member of College staff $(\quad)-30$

An organisation without

College responsibility

for funding

( ) 20
(8) Does this matter offend:

Psychologists

Social workers

The Prince of Wales

College staff

() 10

() 5

( ) -5

() -10

TOTAL SCORE:

*(This document has been reprinted without the authority of any College Committee or Section!)

Allium PORrum

\section{Psychiatry in bookshops}

DeAR Sirs

There is current debate about the position of psychiatry in the 1990s. Within the profession there seems to be a consensus that psychiatry is a medical subspeciality. But what do the general public think?

A well-known Bristol academic bookshop may have the answer. Their psychiatry section is not to be found between pathology and radiology but appears separately, next to Alternative medicine.

Presumably customers find this arrangement more suitable.

I wonder what the situation is like nationally?

Royal United Hospital, Bath

DARRYL WATTS

\section{On-call system for child psychiatry}

DeAr Sirs

Since writing the article on the state of liaison in psychiatry (Psychiatric Bulletin, June 1990, 14, 322) it has been brought to my attention that an extensive on-call system exists for child psychiatry in Bloomsbury.

Department of Maxillofacial Surgery

\& Oral Medicine

Eastman Dental Hospital,
Charlotte Feinmann 